\title{
Chain-Growth Suzuki Polymerization of n-Type Fluorene Copolymers
}

\author{
Einat Elmalem, ${ }^{\dagger}$ Anton Kiriy, ${ }^{\ddagger}$ and Wilhelm T. S. Huck ${ }^{*,+}$, \\ ${ }^{\dagger}$ Melville Laboratory for Polymer Synthesis, Department of Chemistry, University of Cambridge, Cambridge CB2 1EW, \\ United Kingdom \\ ${ }^{\ddagger}$ Leibniz-Institut für Polymerforschung Dresden, Hohe Strasse 6, 01069 Dresden, Germany

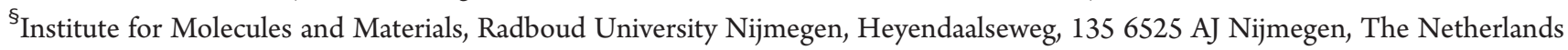 \\ S Supporting Information
}

C onjugated, semiconducting fluorene copolymers are a major class of materials for organic light-emitting diodes (OLEDs) and photovoltaic (PV) applications. ${ }^{1,2}$ These materials are typically prepared via a step-growth condensation polymerization, which gives little or no control over molecular weight (MW), polydispersity (PDI), or end-groups. ${ }^{3,4}$ The development of synthetic routes to polymerize $\pi$-conjugated polymers using "living" polymerizations $s^{5}$ is of great importance as it gives access to conjugated polymers with well-defined structures and conjugated block copolymers. Recently, a number of p-type (or hole-conducting) polymers such as polythiophenes, ${ }^{6-11}$ polyphenylene, ${ }^{12}$ polyfluorenes, ${ }^{13}$ and polypyrroles ${ }^{14}$ have been synthesized in a controlled manner using nickel-catalyzed Kumada chain-growth polymerizations. Only a limited number of n-type copolymers have been reported, ${ }^{15,16}$ reflecting inefficient cross-propagation as well as an incomplete mechanistic understanding of the key parameters that control chain growth. ${ }^{10,17}$

Furthermore, the method has not been applied to n-type conjugated polymers, possibly due to the incompatibility of the catalysts with those monomers. Suzuki coupling of aryl halides with organoboron compounds is a robust route to conjugated polymers and potentially applicable to a wide range of donor and acceptor groups under mild experimental conditions. ${ }^{18}$ Recently, several examples of chain-growth Suzuki polycondensation of aromatic monomers containing bromo- and boronic ester functionality using $t \mathrm{Bu}_{3} \mathrm{PPd}(\mathrm{Ph}) \mathrm{Br}$ as a catalyst have been reported.,19-21 In these examples the phenyl group of the three-coordinated Pd complex acted as an initiator for the chaingrowth polymerization. ${ }^{22}$ This $\mathrm{Pd}$ complex is very reactive due to the bulky electron-donating ligand $\left(t \mathrm{Bu}_{3} \mathrm{P}\right)$ and the vacant coordination site of the complex, ${ }^{22,23}$ which results in preferable intramolecular oxidative addition (OA) over intermolecular catalyst migration, leading to a chain-growth mechanism. ${ }^{24,25}$ This catalyst has been used to obtain polyfluorenes, polyphenylenes, and polythiophenes with narrow PDI, well-defined MW, and controlled end-groups $^{20,21}$ as well as polyfluorene-polyphenylene and polyfluorene-polythiophene block copolymers., ${ }^{9,21}$ Nevertheless, thus far only p-type homo-polyfluorenes have been reported, limiting the use of the method. Here we report the first chain-growth Suzuki polymerization of a monomer consisting of two different aromatic groups, to yield a well-defined electrondeficient polymer, poly $\left(9,9^{\prime}\right.$-dioctylfluorene-co-benzothiadiazole) (pF8BT). Additionally, two different initiator groups have been incorporated in the polymer main chain, demonstrating the versatility of this approach.
A key design feature of our synthetic route is the use of asymmetric $\mathrm{AB}$ monobromo, monoboronic-ester monomers. ${ }^{18,26}$ When the $\mathrm{Pd}$ initiator is introduced to the monomer solution, transmetalation between the catalyst and the $\mathrm{AB}$ monomer leads to an initiation of the polymerization (Scheme 1). Propagation occurs by subsequent reductive elimination, intramolecular migration of the $\mathrm{Pd}$ species to the $\mathrm{C}-\mathrm{Br}$ chain end, followed by oxidative addition. Transmetalation with another monomer then completes the catalytic cycle. If the mechanism operates effectively, all polymer chains carry the initiator moiety and bromine end-groups (or a hydrogen atom that is introduced during the quenching of the polymerization and destruction of the complex). ${ }^{20}$

The synthesis of $\mathrm{AB}$ comonomer F8BT is shown in Scheme 2a. Briefly (for full experimental details see Supporting Information), a symmetric dibromofluorene (1) was activated with butyllithium to introduce a boronic-acid functionality at one side of the molecule (2), which was then protected by using 1,8 diaminonaphthalene (DAN). ${ }^{27,28}$ The bromine was converted into a pinacol-boron group, and monoboronic ester protected fluorene (3) was obtained. Next, a Suzuki-coupling reaction was carried out by dropwise addition of 3 into a solution of dibromobenzo $[c][1,2,5]$ thiadiazole (1.5 equiv) to give the protected comonomer (4) in $60 \%$ yield. Bisarylation has been observed for electron-rich molecules, ${ }^{24,25}$ but here we suspect that the $\mathrm{C}-\mathrm{Br}$ bond of the $\mathrm{BT}$ molecule is more reactive than the $\mathrm{C}-\mathrm{Br}$ bond of 4 , and thus intermolecular $\mathrm{OA}$ leads to the monocoupled product.

It is worth mentioning that although DAN has been reported as a robust protecting-group which can withstand harsh conditions and strong bases (i.e., sodium hydroxide), ${ }^{27,28}$ in our experience the protecting group tended to fall off during Suzuki reaction and column chromatography. Only when a mild fluoride base, i.e. CsF, was used and the reaction was conducted at roomtemperature conditions, decent product yield (60\%) was obtained. The protecting group was removed with hydrochloric acid; also here we encountered difficulties to recover the boronic acid functionality, and several byproducts, albeit in small quantities, were observed. The last reaction was esterification under Dean-Stark conditions of the boronic acid to a pinacol group to obtain monobromo, monoboronic ester AB F8BT comonomer (5) after column purification.

Received: August 25, 2011

Revised: October 5, 2011

Published: October 26, 2011 
Scheme 1. Proposed Chain-Growth Suzuki Mechanism for Polymerization of AB Monomers

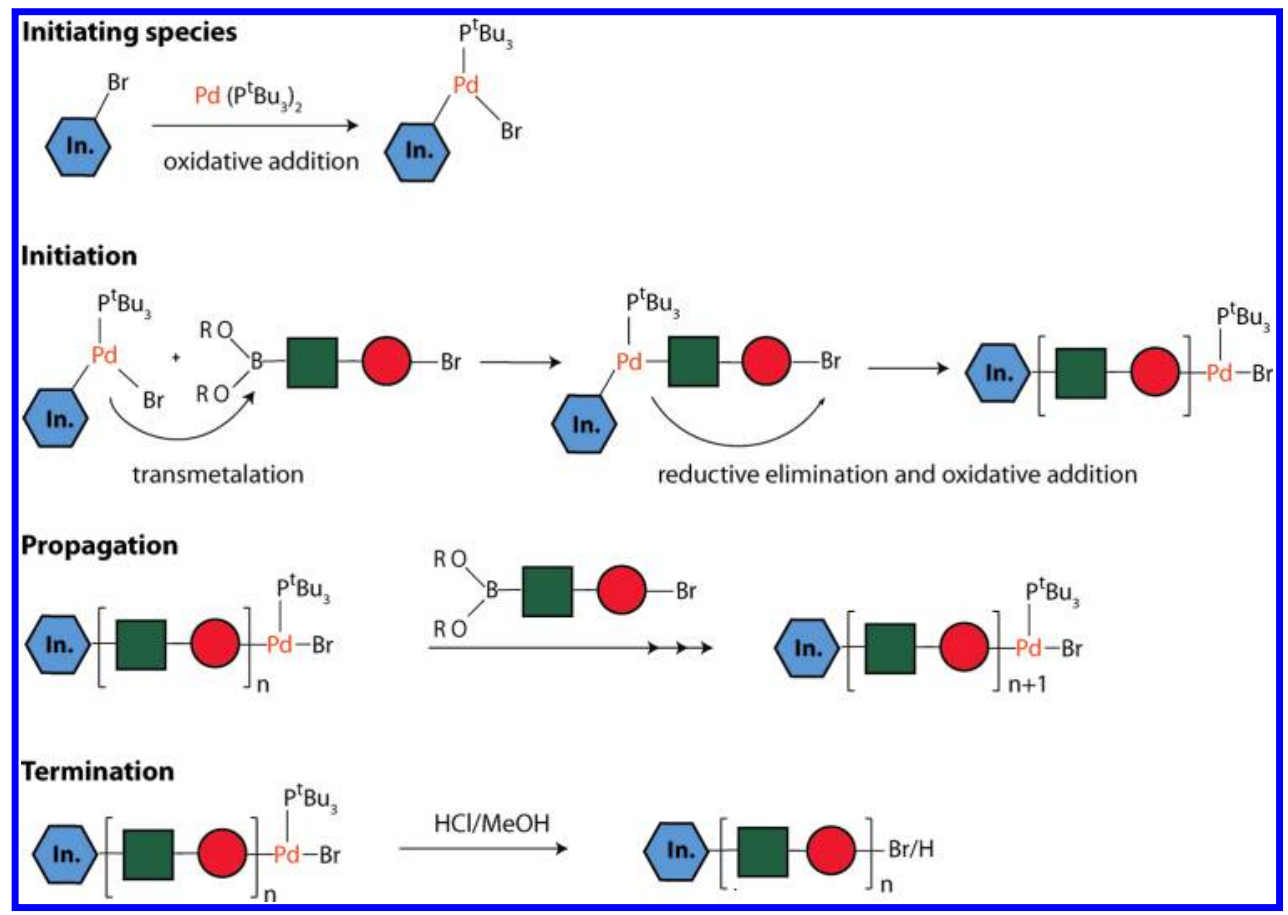

The polymerization of $\mathbf{5}$ (Scheme $2 \mathrm{~b}$ ) was initiated from $5 \mathrm{~mol} \%$ $6 \mathbf{a}$ in THF at $0{ }^{\circ} \mathrm{C}$, using $2 \mathrm{M} \mathrm{CsF}$ as a base and crown-ether as phase-transfer catalyst. The polymerization proceeded to completion after $24 \mathrm{~h}$. Samples were taken at regular time intervals during the reaction and analyzed by gel permeation chromatography (GPC) to estimate the relative $M_{n}$ and the PDI of the polymer. Figure 1A shows GPC chromatograms that were obtained after removing the monomer from the mixture (by washing with acetone). Two significant features which are expected for a chain-growth mechanism can distinguished: first, the unimodal elution curves are clearly shifted toward higher MW over time. Second, the PDI is relatively narrow and constant throughout the polymerization reaction (only slightly increases from 1.15 to 1.27 ). After a $24 \mathrm{~h}$ period the $M_{\mathrm{n}}$ of Ph-pF8BT reached $7379 \mathrm{Da}$ (against polystyrene standards, eluent: THF). Table 1 summarizes the $M_{\mathrm{n}}$ and the PDI obtained for the different aliquots. Furthermore, crude GPC samples (no monomer removed) (Figure S1) show that the concentration of the monomer gradually decreased while the polymer peak shifted to higher MW as the polymerization proceeded. This is expected for a chain-growth mechanism and provides further proof for our findings.

The polymerization kinetics of Ph-pF8BT was also followed by matrix-assisted laser desorption ionization time-of-flight (MALDI-TOF) mass spectrometry, and a representative set of data is shown in Figure 1B. Again, the product peaks were shifted to higher molecular weights with increasing reaction times while maintaining a relatively low PDI (as shown in Table 1). Additionally, the polymer end-groups were examined: the major peaks (marked ) correspond to chains with phenyl and bromine endgroups (designated as $\mathrm{Ph} / \mathrm{Br}$ ); minor peaks (marked $\mathrm{O}$ ) correspond to chains with phenyl and hydrogen end-groups $(\mathrm{Ph} / \mathrm{H})$. The presence of a phenyl moiety on every polymer chain (under MALDI-TOF limitations) strongly supports the proposed chain- growth mechanism. ${ }^{20,21}$ It is important to mention that the $\mathrm{Ph} / \mathrm{H}$ polymers originate from $\mathrm{Ph}-\mathrm{pF} 8 \mathrm{BT}-\mathrm{Pd}\left(\mathrm{P}_{\mathrm{Bu}}\right)-\mathrm{Br}$ propagation species after quenching the polymerization with a mixture of methanol:acid, as reported by Yokozawa et al. ${ }^{20,21}$

Encouraged by these findings, the possibility of introducing different initiator groups was explored. ${ }^{29}$ Pyrene-Pd complex $6 \mathbf{b}$ was synthesized by $\mathrm{OA}$ to 1 -bromopyrene in toluene at $70{ }^{\circ} \mathrm{C}$ (see Supporting Information). First, the polymerization of the fluorene monomer 8 to obtain polymer 9 by initiation with $\mathbf{6 b}$ was studied. Figure 2A shows GPC elution curves taken at different times during the reaction. Table 2 shows the recorded $M_{\mathrm{n}}$ and PDI values. As in the previous case, the kinetics imply a chain-growth mechanism since the $M_{\mathrm{w}}$ increases unimodally while the PDI stays narrow (PDI values vary from 1.28 to 1.41 over $3 \mathrm{~h}$ ). The reaction proceeded to completion within $3 \mathrm{~h}$, after which a $M_{\mathrm{n}}$ of $9556 \mathrm{Da}$ was obtained.

MALDI-TOF measurements (Figure 2B) are in agreement with the GPC data and give additional information about the absolute MW and the end-groups. Similar to the phenyl initiator 6a, almost all polymers chains bear the pyrene as an initiator group. The other end of the chains are terminated either with bromine (marked 0 ) or hydrogen atoms (marked $\bigcirc$ ). Small traces of uncontrolled polymerization, which result in $\mathrm{H}-\mathrm{pF} 8-\mathrm{Br}$ and $\mathrm{H}-\mathrm{pF} 8-\mathrm{H}$, are indicated with $\star$ and $\lesssim$, respectively.

Next, the polymerization of F8BT monomer 5 to obtain polymer Pyr-pF8BT (7b) was studied. The polymerization conditions were the same as for polymers $7 \mathbf{a}$ and $\mathbf{8}$. Figure $2 \mathrm{C}$ shows the GPC chromatograms which are shifted toward higher masses as the reaction progresses in a unimodal fashion while retaining a narrow distribution over time (summary is shown in Table 2). MALDITOF measurement of Pyr-pF8BT after $24 \mathrm{~h}$ is shown in Figure 2D, demonstrating controlled end-groups as described before.

The influence of the end-group on the optical properties of the polymers was studied briefly. In Figure S8A absorption spectra of 
Scheme 2. (A) Synthesis Route of the Asymmetric AB Comonomer F8BT via a Boron Protecting Group (DAN); (B) ChainGrowth Polymerization from Two Different Initiating Species $6 \mathrm{a}$ and $6 \mathrm{~b}$

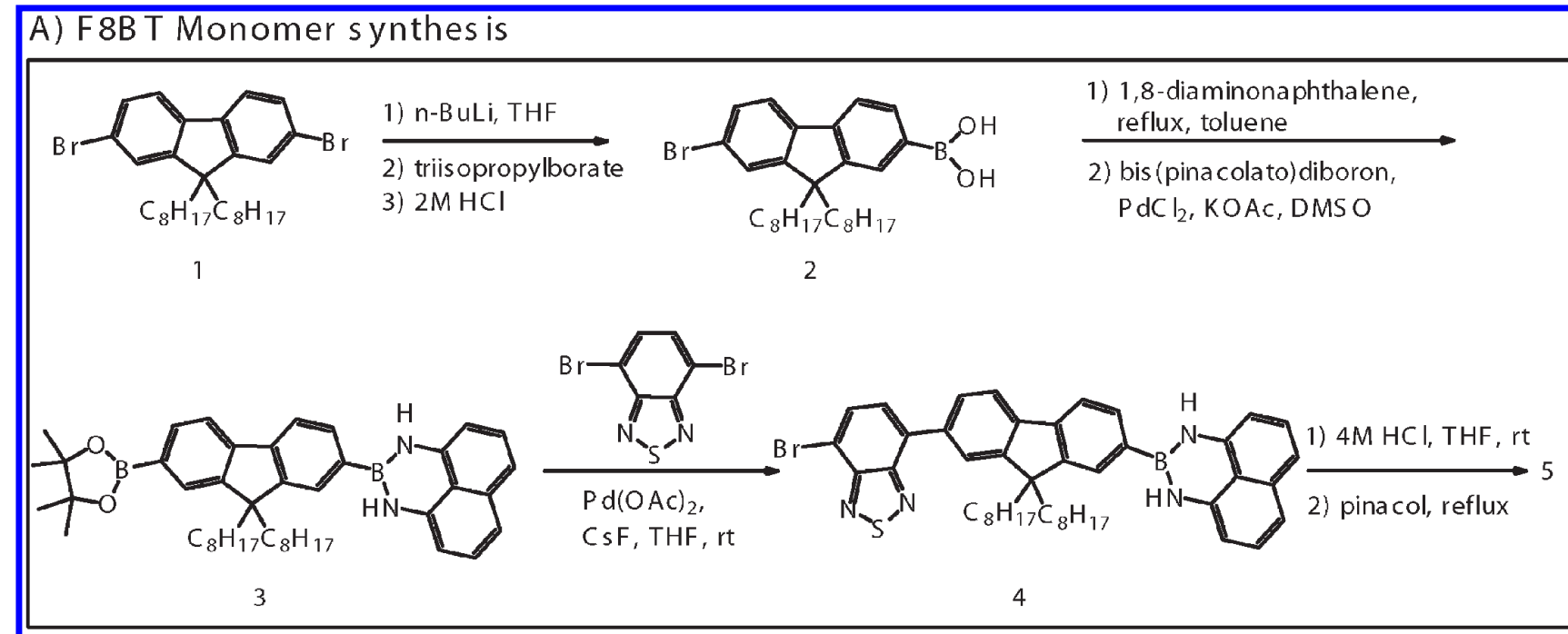

B) Polymerization of F 8BT and F 8
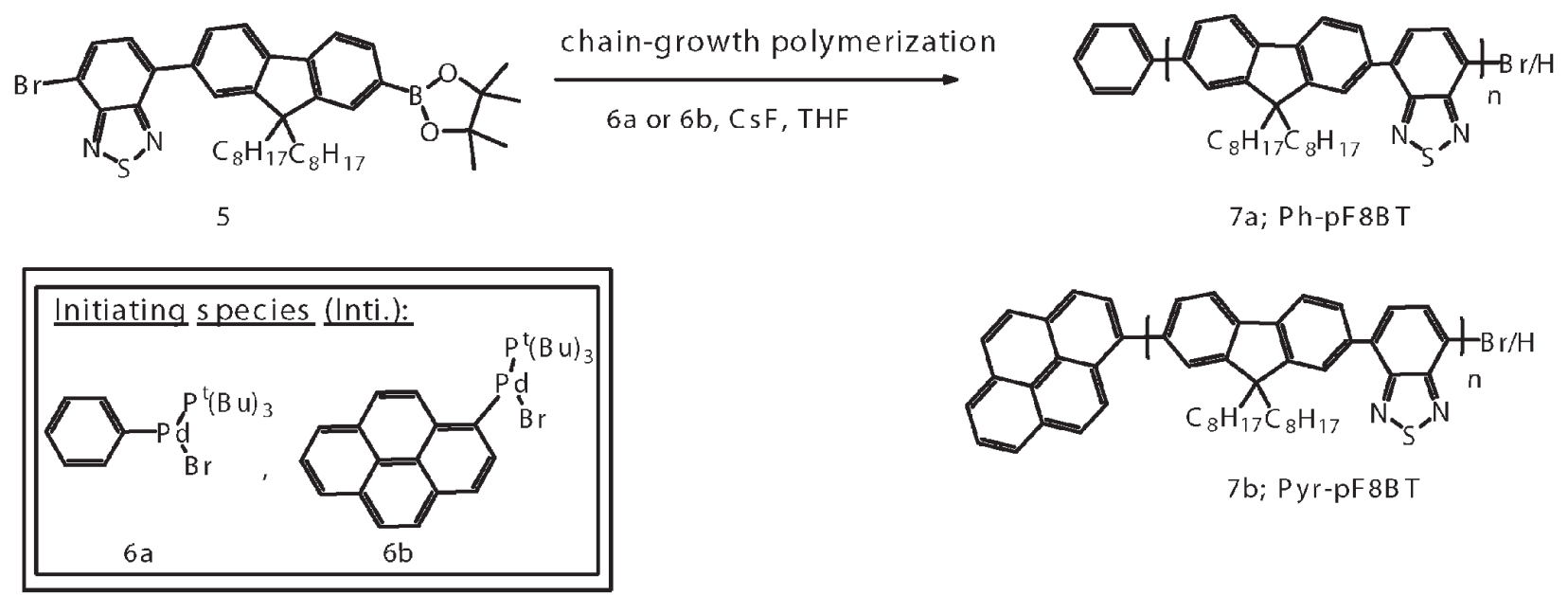

7a; Ph-pF8B T

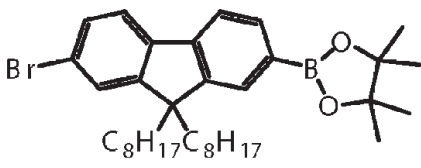

8 chain-growth polymerization

6b, CsF, THF

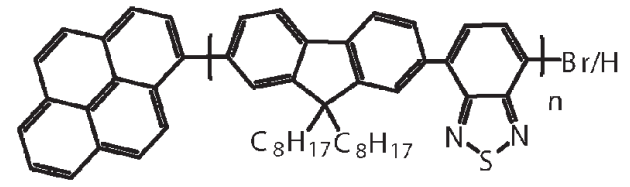

$7 b_{i}$ Pyr-pF8BT
Ph-pF8 and Pyr-pF8 (9) (both polymers have approximately the same $M_{n}$ of $\left.7700 \mathrm{Da}\right)$ at $3.4 \times 10^{-5} \mathrm{M}$ in THF solution are shown. The Pyr-pF8 spectrum is shifted to higher wavelengths in comparison to the spectra of Ph-pF8 (from 395 to $386 \mathrm{~nm}$ in the polymer band gap peak for Ph-pF8 and Pyr-pF8, respectively). Furthermore, one can see that the Pyr-pF8 has better absorption properties than the $\mathrm{Ph}-\mathrm{pF} 8$ (the measured absorption coefficient are $81 \times 10^{3}$ and $45 \times 10^{3} \mathrm{~cm} / \mathrm{M}$, respectively, at the band-gap wavelength). However, when the absorption spectra of PhpF8BT (7a) and Pyr-pF8BT (7b) (both polymers have approximately the same $M_{n}, 7500 \mathrm{Da}$ ) were compared (Figure S8B), neither measurable shift in the wavelength nor significant differences in the absorption properties were observed (absorption coefficient for Pyr-pF8BT and Ph-pF8BT are $3 \times 10^{3}$ and $2 \times$ $10^{3} \mathrm{~cm} / \mathrm{M}$, respectively, at $415 \mathrm{~nm}$ which is the polymer band gap). These observations can be rationalized by the energetic overlap of the frontier orbitals. Indeed, the calculated HOMO LUMO energies of pyrene $(-5.62 \text { and }-2.34 \mathrm{eV} \text {, respectively })^{30}$ are very close to the reported values ${ }^{31}$ for $\mathrm{pF} 8(-5.7$ and $-2.4 \mathrm{eV})$, whereas pF8BT $(-5.9$ and $-3.3 \mathrm{eV})$ has energetically distant orbitals. Additionally, in both of the pyrene cap polymers, the pyrene peak at $280 \mathrm{~nm}$ can be observed. 


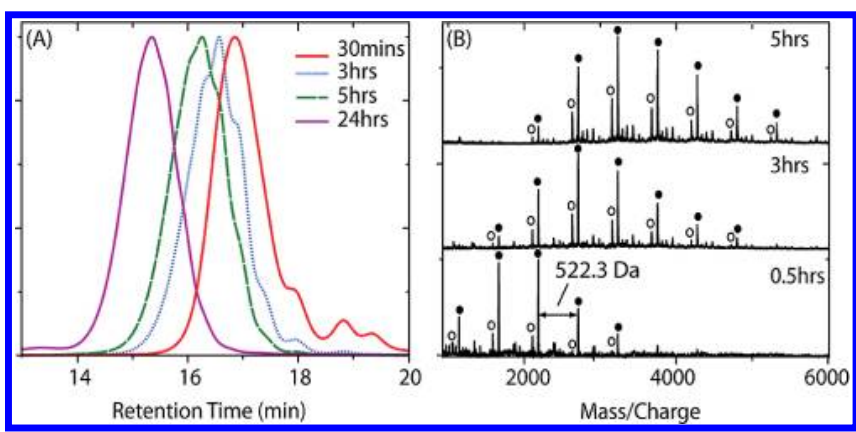

Figure 1. (A) GPC profiles and (B) MALDI-TOF mass spectra of $\mathrm{Ph}$ pF8BT $(7 \mathbf{a})$ obtained at $[5]_{0} /[6 \mathbf{6}]_{0}=20$. (A) The unimodal curves from different reaction time show constant shift to higher $M_{n}$. (B) MALDI shows similar shift to higher masses while the reaction progressed. $\mathrm{Ph} / \mathrm{Br}=\mathbf{0} ; \mathrm{Ph} / \mathrm{H}=\mathrm{O}$.

Table 1. Polymerization of 5 by Initiation with $6 a^{a}$

$\begin{array}{ccccc}\text { time }(\mathrm{h}) & M_{\mathrm{n}}{ }^{b}(\mathrm{Da}) & \mathrm{PDI}^{b} & M_{\mathrm{n}}{ }^{c}(\mathrm{Da}) & \mathrm{PDI}^{c} \\ 0.5 & 3339 & 1.15 & 2098 & 1.09 \\ 3 & 4890 & 1.20 & 3374 & 1.11 \\ 5 & 6053 & 1.22 & 4172 & 1.11 \\ 24 & 7379 & 1.27 & -^{d} & -^{d}\end{array}$

${ }^{a}$ Polymerization was carried out at $[5]_{0} /[6 \mathbf{6 a}]_{0}=20$ in THF. ${ }^{b}$ Estimated by GPC based on polystyrene standards (eluent:THF). ${ }^{c}$ Average values were calculated from MALDI-TOF measurements (see Supporting Information for details). ${ }^{d}$ Not determined.
In conclusion, we have demonstrated how Suzuki condensation polymerization can be performed in a chain-growth fashion in order to yield well-defined fluorene n-type copolymers. To the best of our knowledge, it is the first report on the chain-growth polymerization of electron-conducting monomers. A control over MW, narrow PDI, and specific end-functions has been demonstrated by means of GPC and MALDI-TOF measurements. MALDI-TOF revealed that every polymer chain carries the initiator aromatic moiety and $\mathrm{a} \mathrm{Br}$ or $\mathrm{H}$ on the other side, which is in agreement with the proposed chain-growth mechanism.

Table 2. Polymerization of 5 and 8 by Initiation with $6 b^{a}$

$\begin{array}{lccc}\text { polymer } & \text { time }(\mathrm{h}) & M_{\mathrm{n}}(\mathrm{Da}) & \text { PDI } \\ \text { Pyr-pF8 } & 0.5 & 4470^{b} & 1.28^{b} \\ \text { Pyr-pF8 } & 1.5 & 6871^{b} & 1.33^{b} \\ \text { Pyr-pF8 } & 3 & 9556^{b} & 1.41^{b} \\ \text { Pyr-pF8 } & 3 & 6512^{c} & 1.21^{c} \\ \text { Pyr-pF8BT } & 0.5 & 3974^{b} & 1.19^{b} \\ \text { Pyr-pF8BT } & 1.5 & 5438^{b} & 1.16^{b} \\ \text { Pyr-pF8BT } & 3 & 6429^{b} & 1.23^{b} \\ \text { Pyr-pF8BT } & 24 & 7698^{b} & 1.29^{b} \\ \text { Pyr-pF8BT } & 24 & 5316^{c} & 1.04^{c}\end{array}$

${ }^{a}$ Polymerization was carried out at $[\text { monomer }]_{0} /[6 \mathbf{b}]_{0}=20$ in THF.

${ }^{b}$ Estimated by GPC based on polystyrene standards (eluent:THF).

${ }^{c}$ Average values were calculated from MALDI-TOF measurements (see Supporting Information for more details).

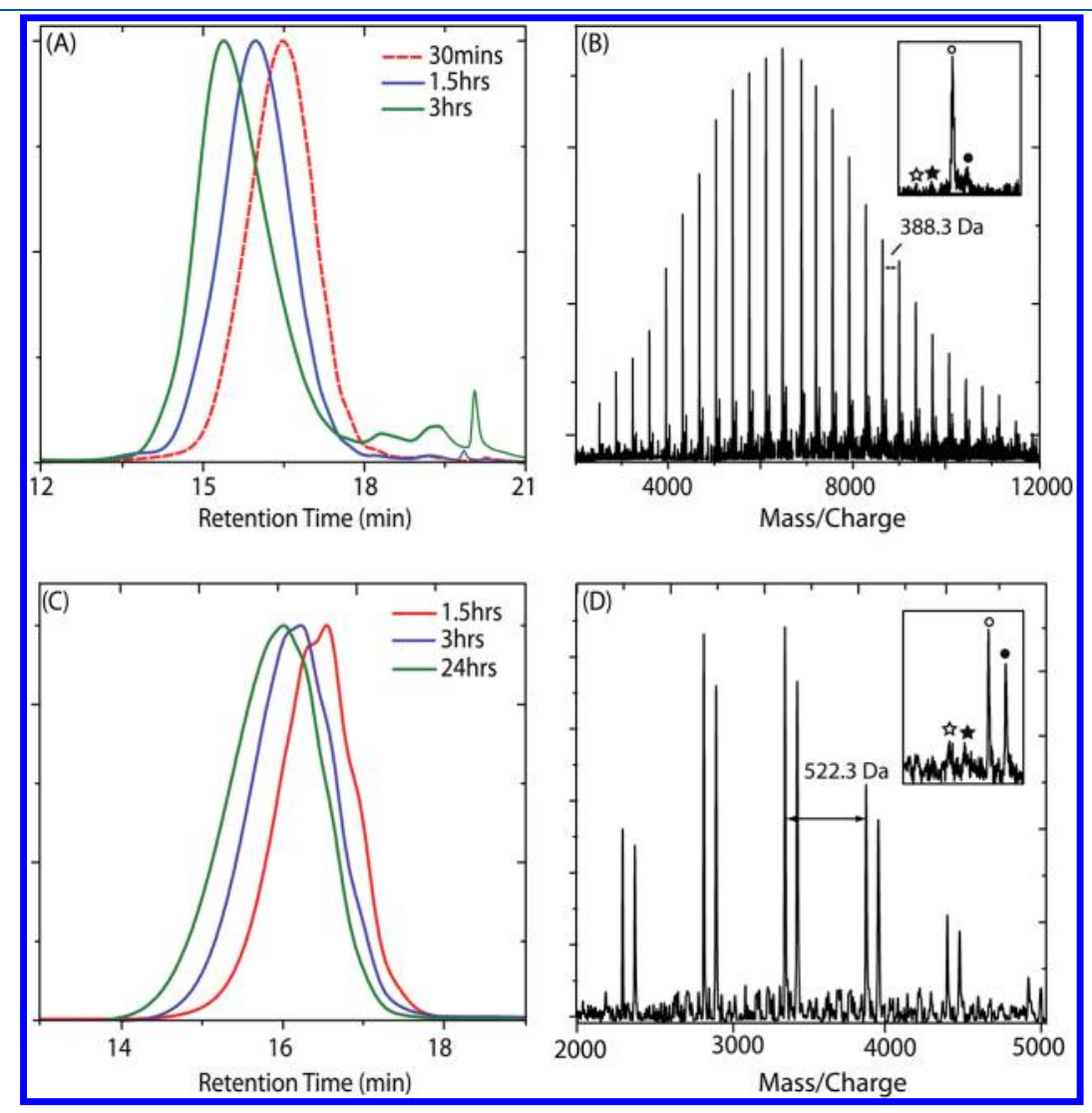

Figure 2. GPC profiles (A, C) and MALDI-TOF mass spectrum (B, D) of Pyr-pF8 and Pyr-pF8BT, respectively, obtained at $[\text { monomer }]_{0} /[6 \mathbf{b}]_{0}=20$. $(A, C)$ The unimodal curves show shift to high $M_{\mathrm{n}}$ during the reaction. (B, D) Inserts show zoom-in of the end-groups functionality, where $\mathrm{Ph} / \mathrm{Br}=\boldsymbol{\bullet}, \mathrm{Pyr} / \mathrm{H}=\mathrm{O}, \mathrm{H} / \mathrm{Br}=\star$, and $\mathrm{H} / \mathrm{H}=\stackrel{i}{\text { r }}$. 
Functional initiators were used to subtly change the optical properties of the conjugated polymers. Although the molecular weights of the polymers obtained in this first study were still quite modest, these results provide a foundation for further experiments to explore different catalysts, initiators, and monomers to improve the versatility of controlled Suzuki coupling polymerization.

\section{ASSOCIATED CONTENT}

S Supporting Information. Detailed experimental procedures of small molecules and polymers and their characterizations, additional GPC curve, UV-vis and photoluminescence spectra. This material is available free of charge via the Internet at http://pubs.acs.org.

\section{AUTHOR INFORMATION}

\section{Corresponding Author}

*E-mail: wtsh2@cam.ac.uk, w.huck@science.ru.nl.

\section{ACKNOWLEDGMENT}

We are grateful for the financial support from the Engineering and Physical Sciences Research Council (ESPRC) (project EP/ G060738/1) and Cambridge Display Technology (CDT). We gratefully acknowledge CDT for a generous supply of starting materials for monomer synthesis. A.K. thanks the DFG for financial support (SPP 1355 "Elementary Processes of Organic Photovoltaics”, project KI-1094/4-1). E.E. thanks Frank Biedermann for useful discussions.

\section{REFERENCES}

(1) Grimsdale, A. C.; Leok Chan, K.; Martin, R. E.; Jokisz, P. G.; Holmes, A. B. Chem. Rev. 2009, 109, 897-1091.

(2) Hains, A. W.; Liang, Z.; Woodhouse, M. A.; Gregg, B. A. Chem. Rev. 2010, 110, 6689-6735.

(3) Scherf, U.; Gutacker, A.; Koenen, N. Acc. Chem. Res. 2008, 41, 1086-1097.

(4) Lohwasser, R. H.; Thelakkat, M. Macromolecules 2011, 44, 3388-3397.

(5) Yokoyama, A.; Yokozawa, T. Macromolecules 2007, 40, 40934101.

(6) Miyakoshi, R.; Yokoyama, A.; Yokozawa, T. J. Am. Chem. Soc. 2005, 127, 17542-17547.

(7) Beryozkina, T.; Senkovskyy, V.; Kaul, E.; Kiriy, A. Macromolecules 2008, 41, 7817-7823.

(8) Tkachov, R.; Senkovskyy, V.; Komber, H.; Sommer, J. U.; Kiriy, A. I. Am. Chem. Soc. 2010, 132, 7803-7810.

(9) Yokozawa, T.; Suzuki, R.; Nojima, M.; Ohta, Y.; Yokoyama, A. Macromol. Rapid Commun. 2011, 32, 801-806.

(10) Lanni, E. L.; McNeil, A. J. J. Am. Chem. Soc. 2009, 131, 16573-16579.

(11) Bronstein, H. A.; Luscombe, C. K. J. Am. Chem. Soc. 2009, $131,12894$.

(12) Miyakoshi, R.; Shimono, K.; Yokoyama, A.; Yokozawa, T. J. Am. Chem. Soc. 2006, 128, 16012-16013.

(13) Huang, L.; Wu, S. P.; Qu, Y.; Geng, Y. H.; Wang, F. S. Macromolecules 2008, 41, 8944-8947.

(14) Stefan, M. C.; Javier, A. E.; Osaka, I.; McCullough, R. D. Macromolecules 2009, 42, 30-32.

(15) Miyakoshi, R.; Yokoyama, A.; Yokozawa, T. Chem. Lett. 2008, 37, 1022-1023.

(16) Javier, A. E.; Varshney, S. R.; McCullough, R. D. Macromolecules 2010, 43, 3233-3237.
(17) Lanni, E. L.; Locke, J. R.; Gleave, C. M.; McNeil, A. J. Macromolecules 2011, 44, 5136-5145.

(18) Sakamoto, J.; Rehahn, M.; Wegner, G.; Schluter, A. D. Macromol. Rapid Commun. 2009, 30, 653-687.

(19) Beryozkina, T.; Boyko, K.; Khanduyeva, N.; Senkovskyy, V.; Horecha, M.; Oertel, U.; Simon, F.; Stamm, M.; Kiriy, A. Angew. Chem., Int. Ed. 2009, 48, 2695-2698.

(20) Yokoyama, A.; Suzuki, H.; Kubota, Y.; Ohuchi, K.; Higashimura, H.; Yokozawa, T. I. Am. Chem. Soc. 2007, 129, 7236.

(21) Yokozawa, T.; Kohno, H.; Ohta, Y.; Yokoyama, A. Macromolecules 2010, 43, 7095-7100.

(22) Stambuli, J. P.; Incarvito, C. D.; Buhl, M.; Hartwig, J. F. J. Am. Chem. Soc. 2004, 126, 1184-1194.

(23) Littke, A. F.; Dai, C. Y.; Fu, G. C. I. Am. Chem. Soc. 2000, 122, 4020-4028.

(24) Dong, C. G.; Hu, Q. S. I. Am. Chem. Soc. 2005, 127, 10006-10007.

(25) Weber, S. K.; Galbrecht, F.; Scherf, U. Org. Lett. 2006, 8, 4039-4041.

(26) Schluter, A. D. J. Polym. Sci., Part A: Polym. Chem. 2001, 39, $1533-1556$.

(27) Noguchi, H.; Hojo, K.; Suginome, M. J. Am. Chem. Soc. 2007, $129,758-759$.

(28) Noguchi, H.; Shioda, T.; Chou, C. M.; Suginome, M. Org. Lett. 2008, 10, 377-380.

(29) Smeets, A.; Willot, P.; De Winter, J.; Gerbaux, P.; Verbiest, T.; Koeckelberghs, G. Macromolecules 2011, 44, 6017-6025.

(30) Shukla, D.; Welter, T. R.; Robello, D. R.; Giesen, D. J.; Lenhard, J. R.; Ahearn, W. G.; Meyer, D. M.; Rajeswaran, M. J. Phys. Chem. C 2009, 113, 14482-14486.

(31) Chua, L.-L.; Zaumseil, J.; Chang, J.-F.; Ou, E. C. W.; Ho, P. K. H.; Sirringhaus, H.; Friend, R. H. Nature 2005, 434, 194-199. 